\title{
Mass Synthesis in Polyol of Tailored Zinc Oxide Nanoparticles for Photovoltaic Applications
}

\author{
Mongia Hosni ${ }^{1}$, Ivaylo Hinkov², Christian Ricolleau ${ }^{3}$, Thierry Pauporté ${ }^{4 *}$, Samir Farhat ${ }^{*}$, \\ Noureddine Jouini ${ }^{1}$ \\ ${ }^{1}$ Laboratoire des Sciences des Procédés et des Matériaux, CNRS, LSPM-UPR, Université Paris 13, PRES \\ Sorbonne-Paris-Cité, Villetaneuse, France \\ ${ }^{2}$ Department of Chemical Engineering, University of Chemical Technology and Metallurgy, Sofia, Bulgaria \\ ${ }^{3}$ Laboratoire Matériaux et Phénomènes Quantiques, CNRS, UMR, Université Paris Diderot, Paris, France \\ ${ }^{4}$ Chimie ParisTech, PSL Research University, CNRS, Institut de Recherche de Chimie Paris (IRCP), Paris, France \\ Email: "thierry.pauporte@chimie-paristech.fr, "samir.farhat@lspm.cnrs.fr
}

Received 16 January 2016; accepted 18 February 2016; published 24 February 2016

Copyright (C) 2016 by authors and Scientific Research Publishing Inc.

This work is licensed under the Creative Commons Attribution International License (CC BY).

http://creativecommons.org/licenses/by/4.0/

c) (i) Open Access

\begin{abstract}
Zinc oxide nanoparticles with different sizes and shapes have been synthesized in polyol using a bottom-up approach. We have studied the scale-up of the process to massively produce high quality nanoparticles of controlled size and shape. The scale-up strategy required the effective mixing of reagents using either axial or radial mixing configurations and was experimentally validated by comparing structural properties of particles obtained in a small and a large size reactor. In addition, the flow patterns in these reactors have been calculated using three-dimen- sional turbulent computational fluid dynamics (CFD) simulations. Our results indicate a strong connection between the flow patterns, as obtained by CFD simulations, and the size and shape of the particles. Actually, our pilot scale reactor allowed producing sample aliquots of $\sim 50$ grams with nanoparticle sizes ranging from $8 \mathrm{~nm}$ to $600 \mathrm{~nm}$ and aspect ratio varying from 1 (nanospheres) to 20 (nanorods). After their synthesis, these two nanoparticle classes have been tested as building blocks in D149-dye-sensitized solar cell (DSSC). The measured power conversion efficiency (PCE) was $4.66 \%$ for nanorods shaped particles and $4.21 \%$ for nanospheres. These values were significantly higher than the $3.90 \%$ PCE obtained with commercial Degussa VP20 ZnO nanoparticles.
\end{abstract}

\section{Keywords}

Zinc Oxide, Polyol Process, Nanoparticles, Scale-Up Strategy, Dye-Sensitized Solar Cells

${ }^{*}$ Corresponding authors.

How to cite this paper: Hosni, M., Hinkov, I., Ricolleau, C., Pauporté, T., Farhat, S. and Jouini, N. (2016) Mass Synthesis in Polyol of Tailored Zinc Oxide Nanoparticles for Photovoltaic Applications. Journal of Surface Engineered Materials and Advanced Technology, 6, 1-10. http://dx.doi.org/10.4236/isemat.2016.61001 


\section{Introduction}

There is a crucial need to develop reliable growth techniques capable of yielding high purity semiconducting nanomaterials with controlled size and morphology in industrial quantities to incorporate them in solar energy devices. Indeed, solar energy is considered to be the carbon-neutral primary source of energy and the ultimate solution to reconcile energy and environmental challenges. In this direction, Dye-Sensitized Solar Cells (DSSC) based on oxide semiconductors and organic dyes have emerged as promising cheap alternative to efficient solarenergy conversion [1]-[11]. Indeed, DSSC can generate power from extremely weak indoor lights and is less dependent on the angle of incident lights. Since the pioneering work performed by Grätzel's group in the 90s, the most widely employed DSSC photoanodes have been based on nanocrystalline $\mathrm{TiO}_{2}$ films sensitized by Rucomplexe dyes. Zinc Oxide is an interesting alternative to replace $\mathrm{TiO}_{2}$ since it exhibits a unique combination of potentially interesting properties such as high bulk electron mobility and a very rich variety of nanostructures based on a very wide range of synthesis techniques. Indeed, $\mathrm{ZnO}$ exhibits significantly higher electron mobility $\left(200 \mathrm{~cm}^{2} \cdot \mathrm{V}^{-1} \cdot \mathrm{s}^{-1}\right)$ in comparison with $\mathrm{TiO}_{2}\left(0.1-4 \mathrm{~cm}^{2} \cdot \mathrm{V}^{-1} \cdot \mathrm{s}^{-1}\right)$ [4] [7]. Better electron transport must result in more efficient electron collection and higher efficiency. In addition, the zinc oxide occurs in a very rich variety of structures and offers a wide range of specific surface area necessary to adsorb organic dye molecules. ZnO can be easily grown as nanostructured films and various nanostructures have been described in the literature [12]-[19]. In addition, the synthesis of highly crystalline ZnO layers at low temperature has been performed by several techniques compatible with substrates that do not tolerate heat treatments. Therefore, semi-conducting material could be deposited on flexible substrates based on polymers such as polyethylene permitting lightweight, flexibility, and low cost.

However, in spite of the huge amount of literature produced in the past few years, the reported efficiencies of $\mathrm{ZnO}$-based solar cells are still far from their $\mathrm{TiO}_{2}$ counterparts. The maximum achieved power conversion efficiencies for $\mathrm{TiO}_{2}$ are actually $~ 13 \%$ [20] with very high stability. This performance is reported up to $7.5 \%$ for $\mathrm{ZnO}$ [21]. The origin of this striking difference in performance is attributed to the factors affecting light absorption and electron injection, as well as the transport and recombination rates in the operating device. Mechanisms of electron injection and dye regeneration across the oxide/dye/electrolyte system have been recently studied by Idígoras et al. [22].

Up to now, many approaches have been employed to fabricate zinc oxide powders. The chemical methods such as hydrothermal synthesis [23], sol-gel reaction [24], micro emulsions growth [25], require rigorous manipulations of the reaction conditions and high-temperature of calcination [26] [27] to obtain well-crystallized particles, which may limit the applications of this material.

In this work, the polyol process has been used to produce zinc oxide nanoparticles. Due to its simplicity and versatility, the polyol-mediated route is an interesting bottom-up process proposed for the synthesis of different metal and oxide nanomaterials and has been recently reviewed by Brayner and Fievet [28]. The polyol process was first developed to produce finely divided metallic powders and was patented in 1985 [29]. Due to their hydrogen bonds and relatively high dielectric constant, polyols act as solvents that can dissolve the majority of inorganic precursors as metallic salts. In addition, due to their chelating properties, polyols can also play a role in coordinating solvents, complexants, and surfactants that adsorb on the elementary particle surface during growth, thus preventing their agglomeration. These materials also allow two competitive chemical reactions to occur: reduction and forced hydrolysis. If water is absent in the medium, reduction is favored, and metal can be obtained starting from dissolved metal salts. The presence of water forces the hydrolysis, which leads to the formation of hydroxides and oxides [30]. At the laboratory scale, this method already permitted the rigorous control of the size and shape of such nanomaterials as zinc oxide nanoparticles via adjustment of the reaction stoichiometry, i.e., hydrolysis ratio and basicity [31]. Nevertheless, other parameters such as the efficiency of mixing reagents, could also affect the particle size distribution, especially in highly viscous polyol media and fast and irreversible precipitation reactions. Indeed, contrary to the mixing of gases which is entirely ensured by molecular diffusion, even at low Reynolds numbers, rapid mixing is necessary for the liquid phase due to the small diffusion constants in liquids. After mixing of reagents, precipitation is the result of several mechanisms, i.e. nucleation, growth, and secondary processes such as agglomeration and ripening. Nucleation is the formation of a solid phase from the liquid. This process occurs when a critical number of molecules join together to form a thermodynamically stable aggregate that grows into larger particles via precursor addition. Nucleation and growth are competing phenomena because both steps consume precursor molecules, and therefore, particle size is the result 
of this competition. Notably small particles are produced by high nucleation rates, whereas large particles are produced by low nucleation rates. Hence, because mixing and reaction are connected, the manner in which reagents are mixed can significantly influence the final particle size distribution.

This work presents a scaling-up strategy to produce zinc oxide semi-conducting nanoparticles with controlled properties by the polyol synthesis process. The reactions were first conducted in a laboratory-scale batch stirred reactor to produce nanosphere and nanorod particles. Then, the process was scaled-up with the aim of maintaining the production of nanoparticle with similar characteristics. Dye-sensitized solar cells (DSSCs), built with $\mathrm{ZnO}$ nanospheres and nanorods, were then realized. Their power conversion efficiencies were measured and compared with cells based on a commercial $\mathrm{ZnO}$ powder.

\section{Experimental}

\subsection{Nanoparticle Preparation}

Zinc oxide particles were prepared by extrapolating two different stoichiometric conditions from the laboratory scale reactor leading to either a nanosphere (NS) or a nanorod (NR) morphology. These syntheses were performed in the small-scale reactor (experiment $Z_{1}$ for $N S$ and $Z_{2}$ for NR) and in the pilot scale with either an axial mixing (experiment $Z_{3}$ for $N S$ and $Z_{4}$ for $N R$ ) or a radial mixing (experiment $Z_{5}$ for $N S$ and $Z_{6}$ for $N R$ ). To vary the mixing behavior inside the pilot scale reactor, straight paddles were used for the axial configuration, while a Rushton turbine with six equally spaced blades permitted to generate radial flows. Nanoparticles were obtained from zinc acetate dihydrate $\left[\left(\mathrm{Zn}(\mathrm{OAc})_{2} \cdot 2 \mathrm{H}_{2} \mathrm{O}\right)\right]$, sodium hydroxide $[\mathrm{NaOH}]$ and diethylene glycol (DEG) $\left[\mathrm{O}\left(\mathrm{CH}_{2} \mathrm{CH}_{2} \mathrm{OH}\right)_{2}\right]$ purchased from Sigma-Aldrich. Distilled water was added to adjust the hydrolysis ratio, and ethanol and acetone were used for washing and cleaning the nanoparticle products. All chemicals were of analytical grade and were used without further purification. To control the reaction stoichiometry, we defined the metal concentration in the polyol solution as $\mathrm{z}=\left[\mathrm{Zn}^{2+}\right] \mathrm{mol}$. $\mathrm{L}^{-1}$, the alkaline ratio as $\mathrm{b}=\mathrm{n}_{\mathrm{NaOH}} / \mathrm{n}_{\mathrm{Zn2}+}$ and the hydrolysis ratio as $h=n_{\mathrm{H} 2 \mathrm{O}} / \mathrm{n}_{\mathrm{Zn} 2+}$, where $\mathrm{n}_{\mathrm{NaOH}}, \mathrm{n}_{\mathrm{H} 2 \mathrm{O}}$ and $\mathrm{n}_{\mathrm{Zn} 2+}$ are the number of moles of sodium hydroxide, water (including those of zinc acetate dihydrate) and zinc precursor, respectively. The $\mathrm{z}, \mathrm{b}, \mathrm{h}$ values, as well as the temperatures used in this study and the observed morphology for small and large scale reactors are summarized in Table 1.

At the large pilot scale, the synthesis was achieved in a $4.5 \mathrm{~L}$ stirred and jacketed glass batch reactor with an internal diameter of $150 \mathrm{~mm}$, a double jacket and equipped by a paddle or a Rushton turbine stirrer as shown in Figure 1. In addition, the external reactor surface was insulated from ambient conditions, making the reactor nearly adiabatic. Compared with the small laboratory-scale system (inset Figure 1), this configuration was designed to improve heat exchange in the reactor, thereby minimizing heat loss because the surface-area-to-volume ratio decreases with volume. The stirrer paddle was powered by a 50-watt motor (Heidolph RZR 2021) with a digital display and a speed range of 40 to $2000 \mathrm{rpm}$. Oil was circulated through the reactor jacket from a Julabo PrestoLH40 cryo thermostat unit. The internal reactor temperature was measured using a Pt100 thermometer. This parameter was precisely controlled using a self-optimizing controller (ICC-Intelligent Cascade Control) operating in a wide working range from $228 \mathrm{~K}$ to $523 \mathrm{~K}$ to enable rapid heating and cooling as well as temperature stability.

Table 1. Experimental conditions for $\mathrm{ZnO}$ nanoparticle synthesis in small and large scale reactors.

\begin{tabular}{ccccccc}
\hline Sample & $\mathrm{Z}$ & $\mathrm{b}$ & $\mathrm{h}$ & Temperature (K) & Morphology & Scale \\
\hline $\mathrm{Z}_{1}$ & 0.5 & 4 & 20 & 399 & Nanosphere & Small \\
$\mathrm{Z}_{2}$ & 0.5 & 0 & 5 & 434 & Nanorod & Small \\
$\mathrm{Z}_{3}$ & 0.5 & 4 & 20 & 399 & Nanosphere & Large with straight paddles \\
$\mathrm{Z}_{4}$ & 0.5 & 0 & 5 & 429 & Nanorod & Large with straight paddles \\
$\mathrm{Z}_{5}$ & 0.5 & 4 & 20 & 396 & Nanosphere & Large with Rushton turbine \\
$\mathrm{Z}_{6}$ & 0.5 & 0 & 5 & 427 & Nanorod & Large with Rushton turbine \\
\hline
\end{tabular}




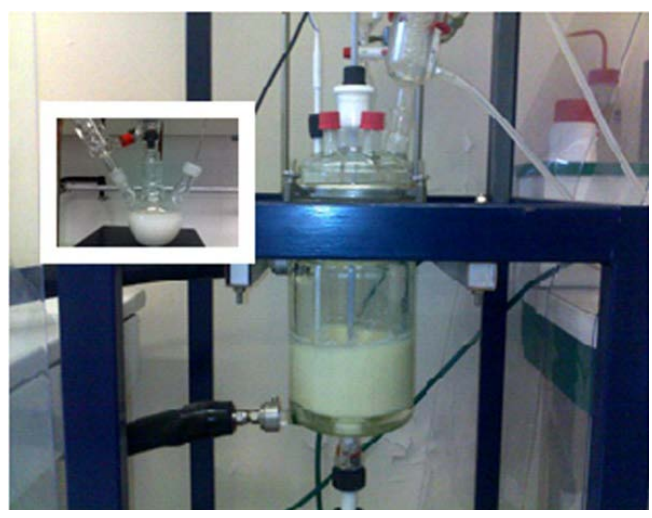

Figure 1. Large versus small (inset) scale reactors photographies.

\subsection{Nanoparticle Characterizations}

The as-prepared powders were structurally characterized using an X-ray diffraction (XRD) INEL diffractometer with $\mathrm{Cu}-\mathrm{K} \alpha 1$ radiation. The nanocrystallite sizes were calculated using Scherrer's equation. The measurements of individual nanoparticle size were performed from transmission electron microscopy (TEM) pictures coupled with the Image $\mathrm{J}$ image analysis software. A statistical analysis was performed on at least 100 nanoparticles from several TEM images. The morphology of the powder was studied by scanning JEOL2011 TEM operating at $200 \mathrm{keV}$. Quantitative high resolution (HRTEM) analyses of single zinc oxide nanoparticles were also performed using a JEOL JEM-ARM200F electron microscope. This microscope combined a cold field emission gun and an aberration corrector on the objective lens [32].

\subsection{Solar Cell Preparation and Characterization}

The dry $\mathrm{ZnO}$ nanoparticle powder was mixed with ethanol, ethyl cellulose and terpineol to form a viscous paste. This paste was deposited onto a Fluorine-doped $\mathrm{SnO}_{2}$ (FTO) coated glass substrates by doctor-blading. The layer was then dried and annealed at $410^{\circ} \mathrm{C}$ for $30 \mathrm{~min}$. The film layer thickness was optimized according to a protocol described in detail in [33]. The oxide film was subsequently sensitized for 2 hours in a solution of 0.5 mM D149 dye (Chemicrea) plus $1 \mathrm{mM}$ of octanoic acid (Aldrich). The cells were assembled as described in [33]. The I-V curves were then recorded by a Keithley 2400 digital sourcemeter, using a $0.01 \mathrm{~V} \cdot \mathrm{s}^{-1}$ voltage sweep rate under one sun illumination with a solar simulator (Abet Technology Sun 2000) filtered to mimic AM 1.5G conditions. The power density was calibrated at $100 \mathrm{~mW} \cdot \mathrm{cm}^{-2}$.

\section{Results and Discussion}

After synthesis, the samples were centrifuged, washed in alcohol and dried at $333 \mathrm{~K}$. The large pilot reactor allowed the production of $\sim 50$ grams of sample aliquots. The TEM pictures of the samples $Z_{1}$ to $Z_{6}$ are shown in Figure 2. From the image analysis, we conclude that the extrapolation of the synthesis conditions from the small to the large reactor was successful. In addition, by varying the stoichiometric conditions, the expected morphology was found. Increasing the alkaline ratio $b$ and the hydrolysis ratio $h$ favors the formation of spherical particles as shown by samples $Z_{1}, Z_{3}$ and $Z_{5}$. Whereas decreasing both of these parameters leads to nanorod shaped particles (samples $Z_{2}, Z_{4}$ and $Z_{6}$ ). Indeed, the relative growth rates of the $\mathrm{ZnO}$ crystal facets are very sensitive to the $\mathrm{OH}$-concentration in the reactor. This parameter could be stoichiometrically adjusted by choosing the appropriate $\mathrm{h}$ and $\mathrm{b}$ parameters thereby controlling the final shape and size of the crystal. To further confirm that the nanoparticles consist of zinc oxide, X-ray diffraction data were collected and displayed in Figure 3. Table 2 summarizes the nanoparticle size characteristics determined from TEM and XRD analyses. The XRD crystallite sizes, calculated from Scherrer's equation, are similar to those obtained from TEM analysis, indicating that the nanoparticles are fairly single crystalline. The lattice constants of zinc oxide hexagonal wurtzite mostly range from 3.247 to $3.286 \AA$ for the a-parameter and from 5.204 to $5.241 \AA$ for the c-parameter. The magnified high resolution TEM views of individual nanorod (Figure 4(a)) and nanosphere (Figure 4(b)) revealed perfect single 


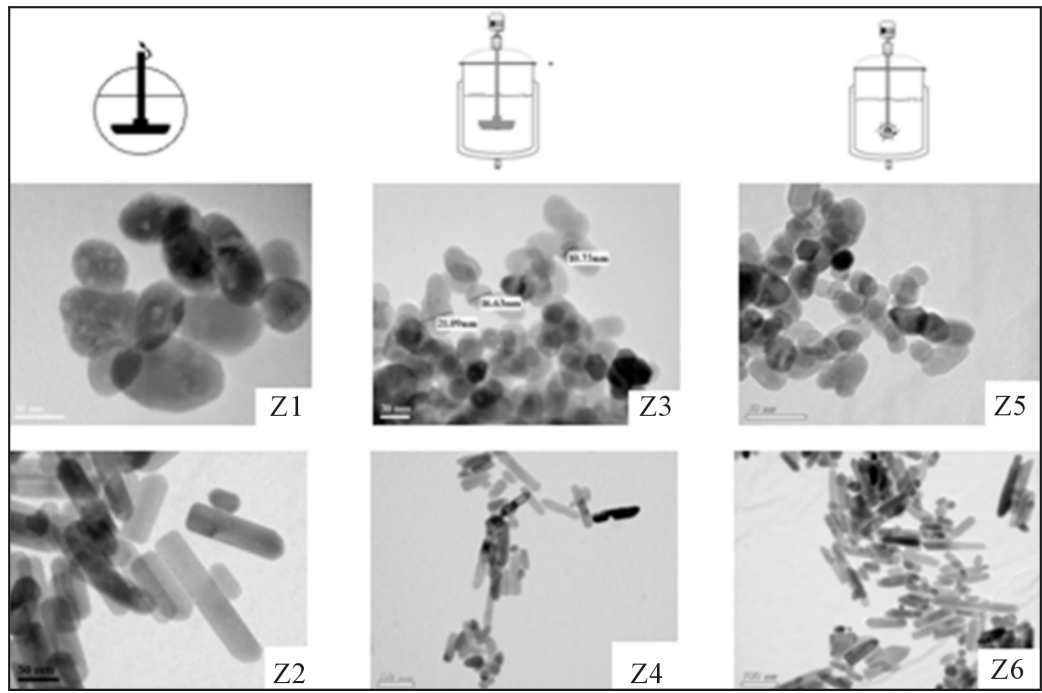

Figure 2. TEM images of the various studied $\mathrm{ZnO}$ nanoparticles prepared in polyol medium.

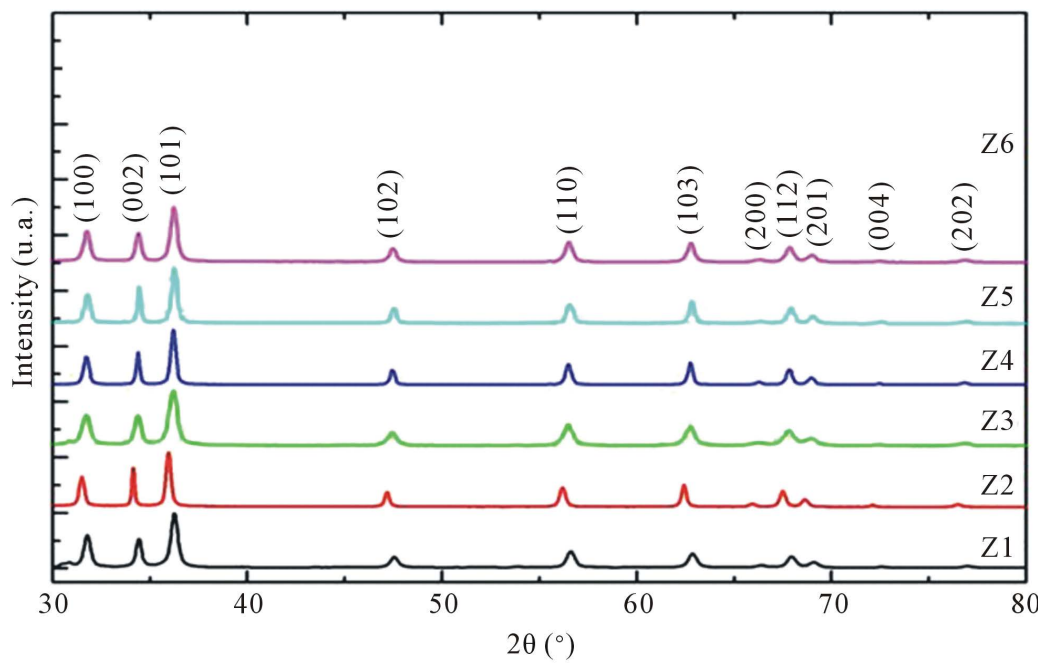

Figure 3. XRD patterns of the $\mathrm{ZnO}$ nanoparticles.
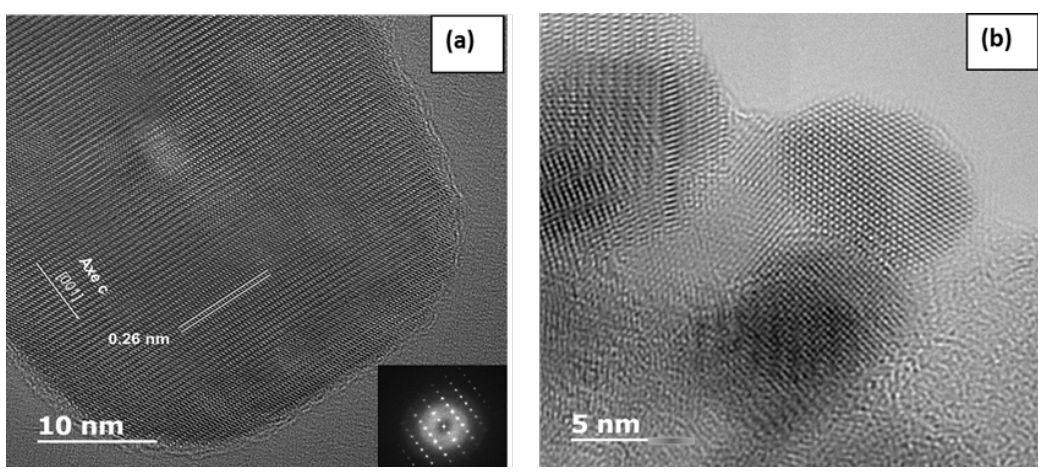

Figure 4. High resolution TEM images of individual $\mathrm{ZnO}$ nanoparticles. (a) Nanorod issued from the pilot reactor $\left(\mathrm{Z}_{4}\right)$ (The insert is a selected area electron diffraction pattern of the image obtained from Fourier transformation) and (b) $\mathrm{ZnO}$ spheres $Z_{3}$. 
Table 2. Zinc oxide nanoparticle sizes obtained from TEM and XRD analysis.

\begin{tabular}{|c|c|c|c|}
\hline Sample & Size from TEM $(\mathrm{nm})$ & Size from XRD (nm) & $\begin{array}{c}\text { Lattice constants } \\
\text { a and c }(\AA)\end{array}$ \\
\hline $\mathrm{Z}_{1}$ & $\mathrm{D}_{\mathrm{TEM}}=27 \pm 0.56$ & $\begin{array}{l}\mathrm{D}_{(100)}=22.3 \\
\mathrm{D}_{(002)}=30.8 \\
\mathrm{D}_{(101)}=22.5\end{array}$ & $\begin{array}{l}\mathrm{a}=3.2523 \\
\mathrm{c}=5.2107\end{array}$ \\
\hline $\mathrm{Z}_{2}$ & $\begin{array}{c}\mathrm{L}_{\mathrm{TEM}}=110 \pm 1.03 \\
\mathrm{D}_{\mathrm{TEM}}=35 \pm 0.30\end{array}$ & $\begin{array}{l}\mathrm{D}_{(100)}=29.8 \\
\mathrm{D}_{(002)}=50.7 \\
\mathrm{D}_{(101)}=30.8\end{array}$ & $\begin{array}{l}\mathrm{a}=3.2619 \\
\mathrm{c}=5.2250\end{array}$ \\
\hline $\mathrm{Z}_{3}$ & $\mathrm{D}_{\mathrm{TEM}}=25 \pm 0.3$ & $\begin{array}{l}\mathrm{D}_{(100)}=19.1 \\
\mathrm{D}_{(002)}=25.4 \\
\mathrm{D}_{(101)}=18.5\end{array}$ & $\begin{array}{l}\mathrm{a}=3.2602 \\
\mathrm{c}=5.2221\end{array}$ \\
\hline $\mathrm{Z}_{4}$ & $\begin{array}{c}\mathrm{L}_{\mathrm{TEM}}=97 \pm 2 \\
\mathrm{D}_{\mathrm{TEM}}=30 \pm 0.50\end{array}$ & $\begin{array}{l}\mathrm{D}_{(100)}=15.8 \\
\mathrm{D}_{(002)}=35.5 \\
\mathrm{D}_{(101)}=15.4\end{array}$ & $\begin{array}{l}\mathrm{a}=3.2594 \\
\mathrm{c}=5.2211\end{array}$ \\
\hline $\mathrm{Z}_{5}$ & $\mathrm{D}_{\mathrm{TEM}}=19 \pm 0.2$ & $\begin{array}{l}\mathrm{D}_{(100)}=17.7 \\
\mathrm{D}_{(002)}=23.6 \\
\mathrm{D}_{(101)}=17.3\end{array}$ & $\begin{array}{l}\mathrm{a}=3.2571 \\
\mathrm{c}=5.2171\end{array}$ \\
\hline $\mathrm{Z}_{6}$ & $\begin{aligned} \mathrm{L}_{\mathrm{TEM}} & =87 \pm 1 \\
\mathrm{D}_{\mathrm{TEM}} & =32 \pm 2\end{aligned}$ & $\begin{array}{l}\mathrm{D}_{(100)}=23.5 \\
\mathrm{D}_{(002)}=30.8 \\
\mathrm{D}_{(101)}=23.5\end{array}$ & $\begin{array}{l}\mathrm{a}=3.2591 \\
\mathrm{c}=5.2211\end{array}$ \\
\hline
\end{tabular}

crystalline zones and a preferred growth direction along the c axis in the case of the naorods (Figure 4(a)).

The spot electron diffraction pattern of the image obtained from Fourier transform analysis and inserted in Figure 4(a) demonstrates the single crystalline nature of the $\mathrm{ZnO}$ materials. Some stacking faults regularly spaced along the revolution axis of the nanorod were also observed. The crystallographic c-axis was parallel to the stacking direction, and the $\mathrm{ZnO}$ nanomaterials grew anisotropically along the (100) plane, which was confirmed by the XRD pattern. When viewed along the (010) direction, the lattice spaces of $0.26 \mathrm{~nm}$ were ascribed to the (002) planes of the hexagonal close-packed (hcp) $\mathrm{ZnO}$ phase. These features are similar to those obtained with the laboratory-scale reactor experiment $\left(\mathrm{Z}_{2}\right)$.

From the analysis of the XRD patterns, the typical object dimensions, perpendicular to the (hkl) plane and noted $\mathrm{D}_{\mathrm{hkl}}$, have been determined. They are plotted in Figure 5. For the nanospheres, all the crystallographic parameters decrease in the following order: $\mathrm{D}_{\mathrm{hkl}}$ small reactor with straight pale $>\mathrm{D}_{\mathrm{hkl}}$ large reactor with straight pale $>D_{\text {hkl }}$ large reactor with Rushton turbine. For the nanorods, the $D_{002}$ parameter, representing the length of the nanorod, decreases in the same manner.

The nanorods are shorter for the syntheses with the Rushton turbine. However, for the large reactor, the use of a Rushton turbine increases the $\mathrm{D}_{100}$ and $\mathrm{D}_{110}$ parameters suggesting an increase in diameter. Assuming the same rate of nucleation, this result can be explained by the mass conservation. In order to compare the flow structure in the three reactors, the spatial distribution of the velocity, the Reynolds number and the rate of turbulent energy dissipation were simulated using the standard $\mathrm{k}-\varepsilon$ turbulence model, implemented in ANSYS Fluent. This tool uses a finite volume method to calculate the flow and the diffusion in three spatial dimensions. The three dimensional geometry was created using ANSYS Design Modeler and the mesh was generated using ANSYS Meshing application. The impeller rotation was modelled using the Multiple Reference Frame (MRF) approach, where the computational grid comprised two meshes: an inner rotating volume enclosing the impeller and an outer stationary volume forming the rest of the reactor and separated by an interface. The interface was defined by the program as an imaginary section to provide the interaction between the rotating and stationary frame. The fluid velocity profiles $\mathrm{v}$, the Reynolds number (Re) and the rate of turbulent energy dissipation $\varepsilon$ are given in Figure 6. From the velocity profiles, we can note the difference in the flow behavior that is axial with the straight paddle and radial for the Rushton turbine. This flow structure affects the residence time of the species in the turbulent zone. For the axial flow, the fluid undergoes downward around the axis and upwardly close to the walls. This causes the development of a circulation loop. For the radial flow, two circulation loops are developed. A small loop is observed under the paddle and a large one above it. Regarding the Reynolds number, spatial distribution is more homogeneous in the case of the Rushton turbine. From Figure 6, we can notice that the 


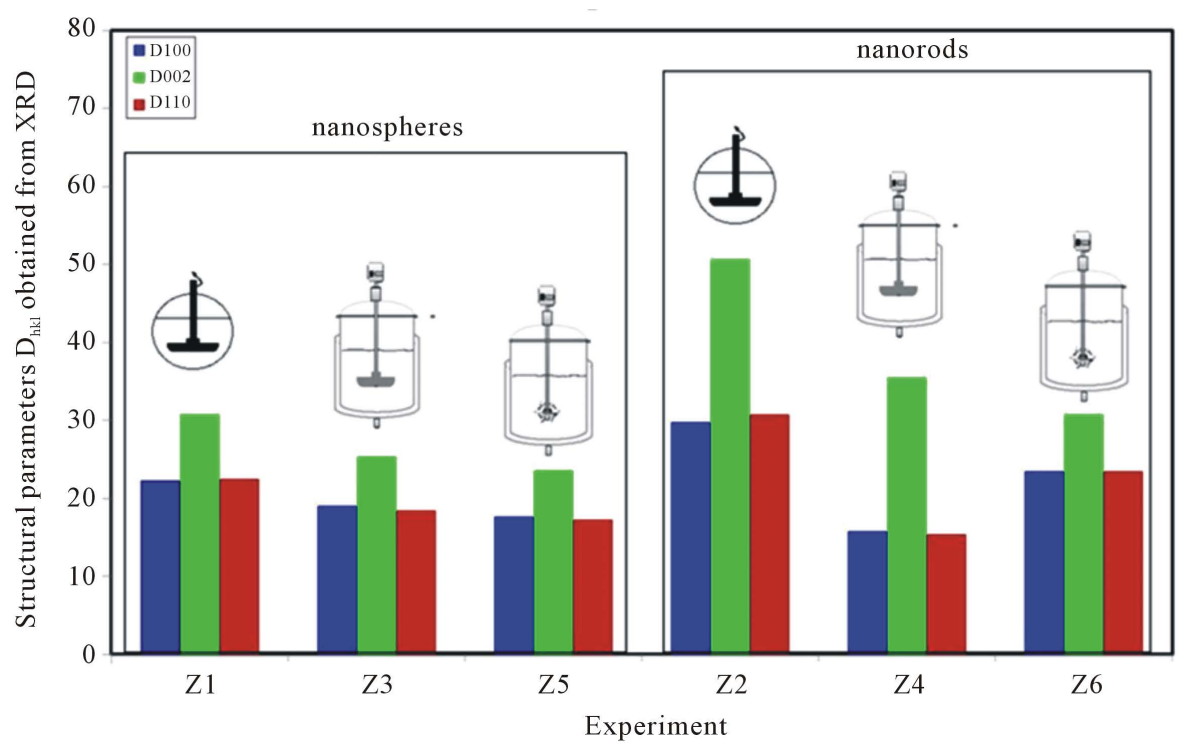

Figure 5. Characteristic $\mathrm{ZnO}$ nanoparticle dimensions in the three main directions obtained from XRD and grouped by classes of morphologies.

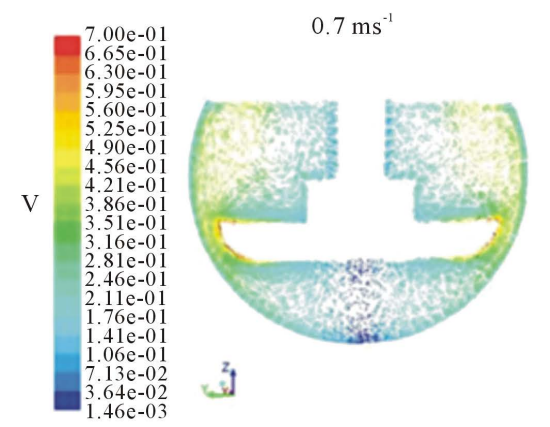

1270

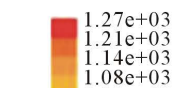

$.14 \mathrm{e}+03$
$.08 \mathrm{e}+03$

$1.02 \mathrm{e}+03$
$9.53 \mathrm{e}+02$

$9.53 \mathrm{e}+02$
$8.80 \mathrm{e}+02$

$8.26 \mathrm{e}+02$
$7.62 \mathrm{e}+02$

$\mathrm{Re}$

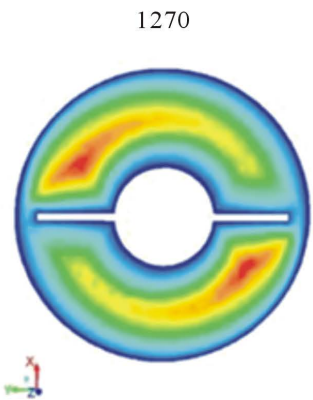

?
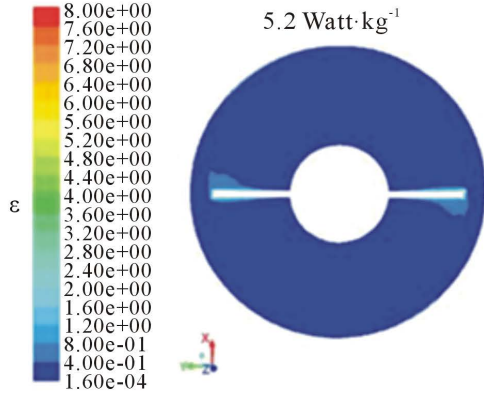

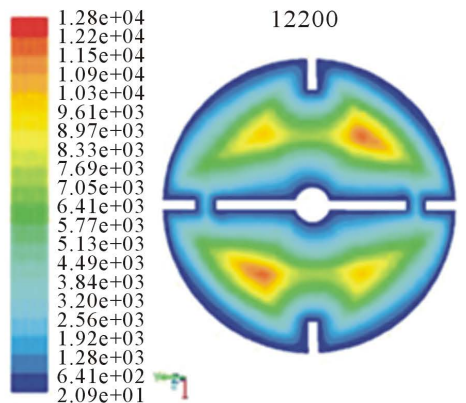

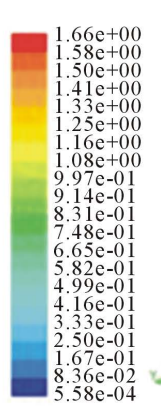

$1.3 \mathrm{~ms}^{-1}$

$6.41 \mathrm{e}+02$
$2.09 \mathrm{e}+01$
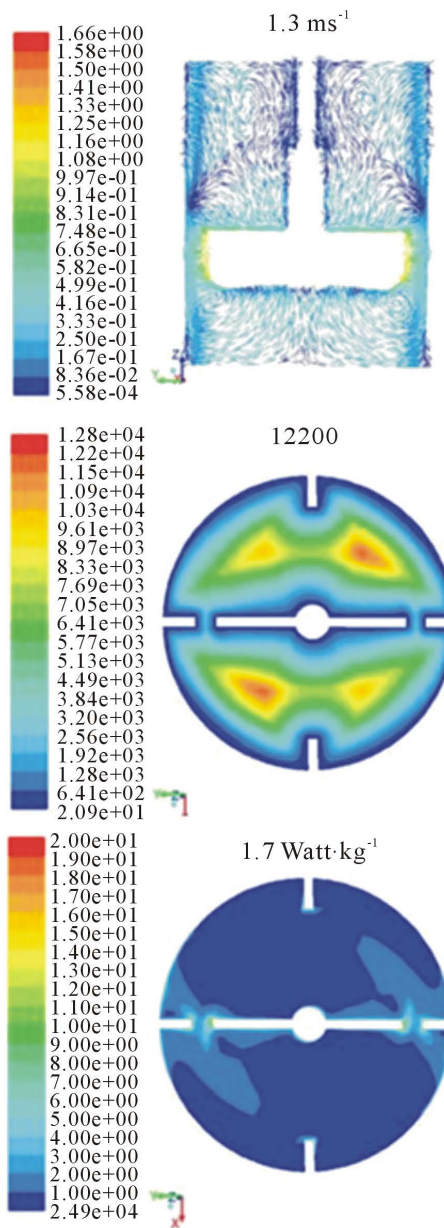
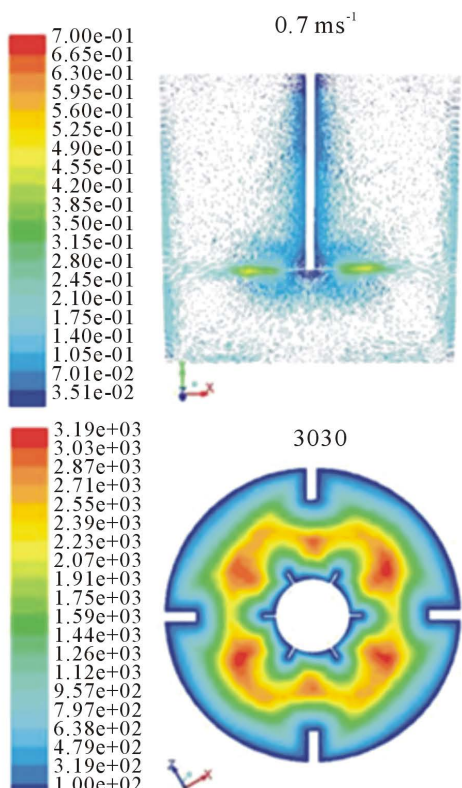

. $190+02$

$.00 \mathrm{e}+02$

$9.00 \mathrm{e}+00$
$8.55 \mathrm{e}+00$
$8.10 \mathrm{e}+00$

$8.10 \mathrm{e}+00$
$7.65 \mathrm{e}+00$
$7.20 \mathrm{e}+00$

$7.20 \mathrm{e}+00$
$6.75 \mathrm{e}+00$

$6.75 \mathrm{e}+00$
$5.85 \mathrm{e}+00$

$5.85 \mathrm{e}+00$

$5.40 \mathrm{e}+00$
$4.95 \mathrm{e}+00$

$+.50 \mathrm{e}+00$

$4.05 \mathrm{e}+00$
$3.60 \mathrm{e}+00$

$3.60 \mathrm{e}+00$
$3.15 \mathrm{e}+00$
$2.70 \mathrm{e}+00$

$2.25 \mathrm{e}+00$

$1.80 \mathrm{e}+00$

$1.35 \mathrm{e}+00$
$9.00 \mathrm{e}-01$

$9.00 \mathrm{e}-01$
$4.50 \mathrm{e}-01$
$2.07 \mathrm{e}-05$

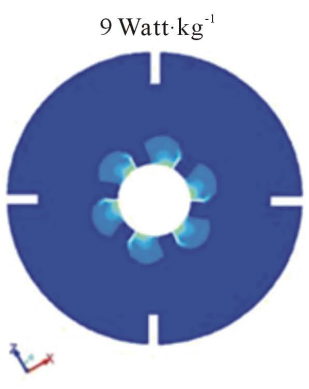

Figure 6. Simulated mapping of velocity $v$, Reynolds number Re and rate of dissipation of turbulent energy $\varepsilon$ in the reactors used in the study. $\mathrm{T}=160^{\circ} \mathrm{C} ; \mathrm{N}=220 \mathrm{RPM}$; Fluid $=$ DEG. 
Rushton turbine provides the best spatial distribution of the dissipation rate of turbulent energy $\varepsilon$ also the best spatial distribution of $\varepsilon$ and can be recommended for the scaling-up of the synthesis of small ZnO nanoparticles. On the other hand, the straight paddle can be used for the synthesis of thin and long nanorods.

To illustrate the concept of the integration of these zinc oxide nanoparticles in DSSC, those issued from experiments $Z_{1}$ and $Z_{2}$ were used to prepare porous semiconductor layers with similar dye loadings. The cell $\mathrm{I}-\mathrm{V}$ curves measured under one sun calibrated light are plotted in Figure 7(a), and the cell characteristics are summarized in Table 3. The measured power conversion efficiency was $4.66 \%$ for the nanorods and $4.21 \%$ for the nanospheres. These values are much higher than 3.90\% obtained with Degussa VP20 commercial ZnO nanoparticles $\left(\mathrm{Z}_{0}\right)$ with a mixed shape between nanorods and nanospheres and $20 \mathrm{~nm}$ mean size. The best measured power conversion efficiency was achieved with the nanorods. This is probably due to their high surface structural quality as shown by Figure 4(a) that favors the dye anchoring and to their larger induced packing pores as schematically presented in Figure 7(b). Larger pores promote the sensitization by the dye, facilitate the penetration and filling of the porous layer with the cell electrolyte solution and redox species diffusion and are finally beneficial for the device performances.

\section{Conclusions}

As a conclusion, polyol process is a bottom-up assembly method that is powerful for creating engineered structures with atomic precision and few defects. This study demonstrates that it is possible to reproduce at larger scale the conditions for forced hydrolysis reaction leading either to nanospheres or nanorods. We can note that the synthesis of all the intermediate sphero-cylindrical systems is also possible by an appropriate choice of the reaction conditions. For the limit cases of spheres and rods, we performed the scaling-up with sample aliquots of $\sim 50$ grams. In academic context, this is useful to elaborate fairly homogenous samples issued from the same batch.

The high viscosity of the polyol medium decreases mass transport and reaction kinetics. To avoid this negative effect, mixing systems must be optimized to facilitate the reactions by the appropriate choice of the local

Table 3. J-V curve parameters of photovoltaic cells (AM1.5G $100 \mathrm{~mW} \cdot \mathrm{cm}^{-2}$ illumination).

\begin{tabular}{ccccc}
\hline Sample & $\mathrm{V}_{\text {OC }}$ & $\mathrm{J}_{\mathrm{SC}}$ & $\mathrm{FF}$ & $\eta(\%)$ \\
\hline $\mathrm{Z}_{0}$ & 0.540 & 10.5 & 69.8 & 3.90 \\
$\mathrm{Z}_{1}$ & 0.554 & 10.5 & 72.4 & 4.21 \\
$\mathrm{Z}_{2}$ & 0.547 & 12.7 & 66.9 & 4.66 \\
\hline
\end{tabular}

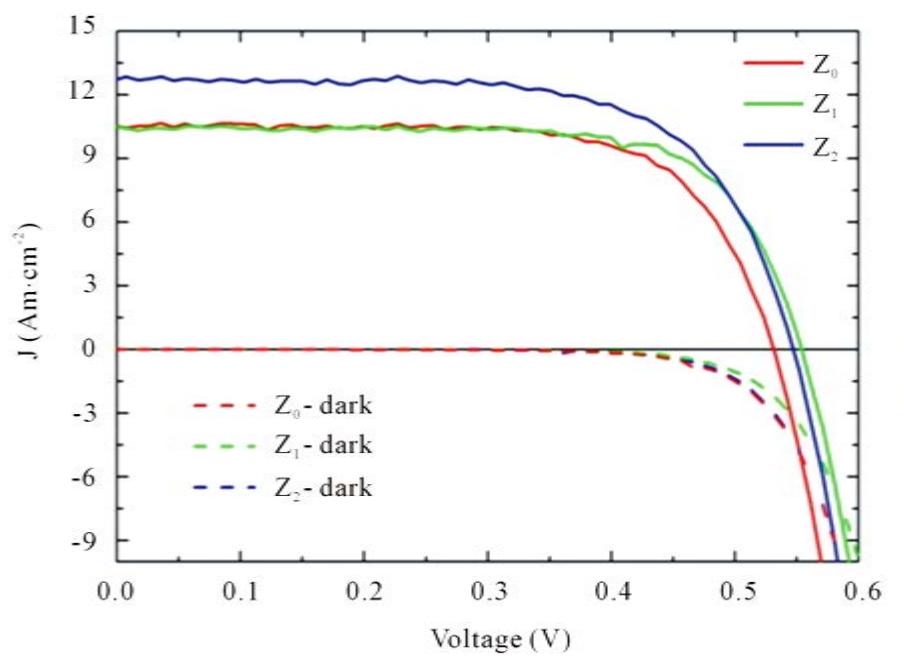

(a)

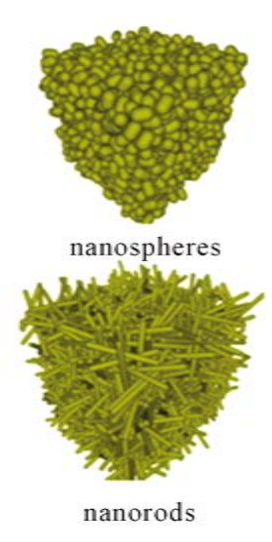

(b)

Figure 7. (a) I-V curves of DSSCs measured under one sun and in the dark. (b) Random packing view of spherical and cylindrical systems. 
dissipated energy. Consequently, in addition to the stoichiometric parameters, it is possible to control local synthesis conditions by simply choosing the mixing system. For zinc oxide, Rushton turbine provides shorter nanoparticles, whereas straight paddles enhance shape anisotropy. This result confirms the strong relationship between the flow patterns and zinc oxide growth habit, supporting the hypothesis that the precipitation of nanoparticles requires high mixing intensity. CFD calculations have facilitated the depiction of the turbulent flow patterns in our reactors and energy dissipation under different impeller geometries, providing a better picture of the mixing efficiency in the reaction vessel. Finally, to illustrate the use of these nanoparticles of zinc oxide in DSSC, two classes of high quality nanoparticles with nanosphere and nanorod shapes have been tested. We have confirmed the significant effect of the nanoparticle morphology on the power conversion efficiency and demonstrated the importance of controlling the particle shape and properties for such an application. These mass synthesized nanoparticles are promising for further applications in photovoltaics and other fields.

\section{Acknowledgements}

IFR Paris Nord Plaine de France (PPF) as well as ANR (Agence Nationale de la Recherche) and CGI (Commissariat à l'Investissement d'Avenir) are gratefully acknowledged for their financial support of this work through Labex SEAM (Science and Engineering for Advanced Materials and devices) ANR 11 LABX 086, ANR 11 IDEX 05 02”.

\section{References}

[1] Hagfeldt, A., Boschloo, G., Sun, L., Kloo, L. and Pettersson, H. (2010) Dye-Sensitized Solar Cells. Chemical Reviews, 110, 6595-6663. http://dx.doi.org/10.1021/cr900356p

[2] Huang, C., Wu, S.-Y., Chang, Y.-C., Pan, C.-H. and Tsai, C.-Y. (2010) The Protection of Flexible DSSC Polymeric Substrate Using Atmospheric Pressure Plasma Coating. Journal of the Chinese Chemical Society, 57, 1208-1211. http://dx.doi.org/10.1002/jccs.201000177

[3] Kalyanasundaram, K. (2010) Dye-Sensitized Solar Cells. EPFL Press, Lausanne.

[4] Kusumawati, Y., Hosni, M., Martoprawiro, M.A., Cassaignon, S. and Pauporté, T. (2014) Charge Transport and Recombination in $\mathrm{TiO}_{2}$ Brookite-Based Photoelectrodes. The Journal of Physical Chemistry C, 118, 23459-23467. http://dx.doi.org/10.1021/jp5047479

[5] Liu, J., Cao, G., Yang, Z., Wang, D., Dubois, D., Zhou, X., Graff, G.L., Pederson, L.R. and Zhang, J.-G. (2008) Oriented Nanostructures for Energy Conversion and Storage. ChemSusChem, 1, 676-697. http://dx.doi.org/10.1002/cssc.200800087

[6] Magne, C., Dufour, F., Labat, F., Lancel, G., Durupthy, O., Cassaignon, S. and Pauporté, T. (2012) Effects of TiO Nanoparticle Polymorphism on Dye-Sensitized Solar Cell Photovoltaic Properties. Journal of Photochemistry and Photobiology A: Chemistry, 232, 22-31. http://dx.doi.org/10.1016/j.jphotochem.2012.01.015

[7] Magne, C., Moehl, T., Urien, M., Gratzel, M. and Pauporté, T. (2013) Effects of ZnO Film Growth Route and Nanostructure on Electron Transport and Recombination in Dye-Sensitized Solar Cells. Journal of Materials Chemistry A, 1, 2079-2088. http://dx.doi.org/10.1039/C2TA00674J

[8] O'Regan, B. and Gratzel, M. (1991) A Low-Cost, High-Efficiency Solar Cell Based on Dye-Sensitized Colloidal TiO 2 Films. Nature, 353, 737-740. http://dx.doi.org/10.1038/353737a0

[9] Xu, F., Dai, M., Lu, Y. and Sun, L. (2010) Hierarchical ZnO Nanowire-Nanosheet Architectures for High Power Conversion Efficiency in Dye-Sensitized Solar Cells. The Journal of Physical Chemistry C, 114, 2776-2782. http://dx.doi.org/10.1021/jp910363w

[10] Yasuo, C., Ashraful, I., Yuki, W., Ryoichi, K., Naoki, K. and Liyuan, H. (2006) Dye-Sensitized Solar Cells with Conversion Efficiency of 11.1\%. Japanese Journal of Applied Physics, 45, L638. http://dx.doi.org/10.1143/JJAP.45.L638

[11] Yella, A., Lee, H.-W., Tsao, H.N., Yi, C., Chandiran, A.K., Nazeeruddin, M.K., Diau, E.W.-G., Yeh, C.-Y., Zakeeruddin, S.M. and Grätzel, M. (2011) Porphyrin-Sensitized Solar Cells with Cobalt (II/III)-Based Redox Electrolyte Exceed 12 Percent Efficiency. Science, 334, 629-634. http://dx.doi.org/10.1126/science.1209688

[12] El Belghiti, H., Pauporté, T. and Lincot, D. (2008) Mechanistic Study of ZnO Nanorod Array Electrodeposition. Physica Status Solidi (a), 205, 2360-2364. http://dx.doi.org/10.1002/pssa.200879443

[13] Cheng, H.-M. and Hsieh, W.-F. (2010) High-Efficiency Metal-Free Organic-Dye-Sensitized Solar Cells with Hierarchical ZnO Photoelectrode. Energy \& Environmental Science, 3, 442-447.

http://dx.doi.org/10.1039/b915725e 
[14] Guerin, V.-M. and Pauporté, T. (2011) From Nanowires to Hierarchical Structures of Template-Free Electrodeposited ZnO for Efficient Dye-Sensitized Solar Cells. Energy \& Environmental Science, 4, 2971-2979. http://dx.doi.org/10.1039/c1ee01218e

[15] Guerin, V.M., Elias, J., Nguyen, T.T., Philippe, L. and Pauporté, T. (2012) Ordered Networks of ZnO-Nanowire Hierarchical Urchin-Like Structures for Improved Dye-Sensitized Solar Cells. Physical Chemistry Chemical Physics, 14, 12948-12955. http://dx.doi.org/10.1039/c2cp42085f

[16] Cheng, H.M., Hsieh, W.F. (2010) Electron Transfer Properties of Organic Dye-Sensitized Solar Cells Based on Indoline Sensitizers with ZnO Nanoparticles. Nanotechnology, 21, 485202. http://dx.doi.org/10.1088/0957-4484/21/48/485202

[17] Le Bahers, T., Labat, F., Pauporté, T., Ciofini, I. (2010) Effect of Solvent and Additives on the Open-Circuit Voltage of ZnO-Based Dye-Sensitized Solar Cells: A Combined Theoretical and Experimental Study. Physical Chemistry Chemical Physics, 12, 14710-14719. http://dx.doi.org/10.1039/c004358c

[18] Lupan, O., Guérin, V.M., Tiginyanu, I.M., Ursaki, V.V., Chow, L., Heinrich, H., Pauporté, T. (2010) Well-Aligned Arrays of Vertically Oriented ZnO Nanowires Electrodeposited on ITO-Coated Glass and their Integration in Dye Sensitized Solar Cells. Journal of Photochemistry and Photobiology A: Chemistry, 211, 65-73. http://dx.doi.org/10.1016/j.jphotochem.2010.02.004

[19] Zhang, Q., Chou, T.P., Russo, B., Jenekhe, S.A., Cao, G. (2008) Aggregation of ZnO Nanocrystallites for High Conversion Efficiency in Dye-Sensitized Solar Cells. Angewandte Chemie International Edition, 47, 2402-2406. http://dx.doi.org/10.1002/anie.200704919

[20] Mathew, S., Yella, A., Gao, P., Humphry-Baker, R., Curchod, B.F.E., Ashari-Astani, N., Tavernelli, I., Rothlisberger, U., Nazeeruddin, M.K. and Grätzel, M. (2014) Dye-Sensitized Solar Cells with 13\% Efficiency Achieved Through the Molecular Engineering of Porphyrin Sensitizers, Nature Chemistry, 6, 242-247. http://dx.doi.org/10.1038/nchem.1861

[21] Memarian, N., Concina, I., Braga, A., Rozati, S.M., Vomiero, A., Sberveglieri, G. (2011) Hierarchically Assembled ZnO Nanocrystallites for High-Efficiency Dye-Sensitized Solar Cells. Angewandte Chemie International Edition, 50, 12321-12325. http://dx.doi.org/10.1002/anie.201104605

[22] Idígoras, J., Burdziński, G., Karolczak, J., Kubicki, J., Oskam, G., Anta, J.A., Ziółek, M. (2015) The Impact of the Electrical Nature of the Metal Oxide on the Performance in Dye-Sensitized Solar Cells: New Look at Old Paradigms. The Journal of Physical Chemistry C, 119, 3931-3944. http://dx.doi.org/10.1021/jp512330f

[23] Zeng, Y., Zhang, T., Qiao, L. (2009) Preparation and Gas Sensing Properties of the Nutlike ZnO Microcrystals via a Simple Hydrothermal Route. Materials Letters, 63, 843-846. http://dx.doi.org/10.1016/j.matlet.2009.01.012

[24] Vafaee, M., Ghamsari, M.S., (2007) Preparation and Characterization of ZnO Nanoparticles by a Novel Sol-Gel Route. Materials Letters, 61, 3265-3268. http://dx.doi.org/10.1016/j.matlet.2006.11.089

[25] Guo, L., Ji, Y.L., Xu, H., Simon, P., Wu, Z. (2002) Regularly Shaped, Single-Crystalline ZnO Nanorods with Wurtzite Structure. Journal of the American Chemical Society, 124, 14864-14865. http://dx.doi.org/10.1021/ja027947g

[26] Hong, R., Pan, T., Qian, J., Li, H. (2006) Synthesis and Surface Modification of ZnO Nanoparticles. Chemical Engineering Journal, 119, 71-81. http://dx.doi.org/10.1016/j.cej.2006.03.003

[27] Ye, J., Zhou, R., Zheng, C., Sun, Q., Lv, Y., Li, C., Hou, X. (2012) Size-Controllable Synthesis of Spherical ZnO Nanoparticles: Size- and Concentration-Dependent Resonant Light Scattering. Microchemical Journal, 100, 61-65. http://dx.doi.org/10.1016/j.microc.2011.09.002

[28] Brayner, R., Fiévet, F., Coradin, T. (2013) The Polyol Process. Nanomaterials: A Danger or a Promise? A Chemical and Biological Perspective. Spriengler-Verlag, London.

[29] Figlarz, M., Fiévet, F. and Lagier, J.P. (1985). French Patent Patent No. 8221483.

[30] Poul, L., Ammar, S., Jouini, N., Fiévet, F., Villain, F. (2003) Synthesis of Inorganic Compounds (Metal, Oxide and Hydroxide) in Polyol Medium: A Versatile Route Related to the Sol-Gel Process. Journal of Sol-Gel Science and Technology, 26, 261-265. http://dx.doi.org/10.1023/a:1020763402390

[31] Dakhlaoui, A., Jendoubi, M., Smiri, L.S., Kanaev, A., Jouini, N. (2009) Synthesis, Characterization and Optical Properties of ZnO Nanoparticles with Controlled Size and Morphology. Journal of Crystal Growth, 311, 3989-3996. http://dx.doi.org/10.1016/j.jcrysgro.2009.06.028

[32] Ricolleau,C., Nelayah, J., Oikawa, T., Kohno, Y., Braidy, N., Wang, G., Hue, F., Florea, L., Pierron Bohnes, V. and Alloyeau, D. (2013) Performances of an 80-200 kV Microscope Employing a Cold-FEG and an Aberration-Corrected Objective Lens Microscopy, 62, 283-293. http://dx.doi.org/10.1093/jmicro/dfs072

[33] Hosni, M., Kusumawati, Y., Farhat, S., Jouini, N., Pauporté, T. (2014) Effects of Oxide Nanoparticle Size and Shape on Electronic Structure, Charge Transport, and Recombination in Dye-Sensitized Solar Cell Photoelectrodes. The Journal of Physical Chemistry C, 118, 16791-16798. http://dx.doi.org/10.1021/jp412772b 